\title{
Immunodeficiency at the Start of Combination Antiretroviral Therapy in Low-, Middle-, and High-Income Countries
}

\author{
The IeDEA and ART Cohort Collaborations
}

\begin{abstract}
Objective: To describe the CD4 cell count at the start of combination antiretroviral therapy (cART) in low-income (LIC), lower middle-income (LMIC), upper middle-income (UMIC), and high-income (HIC) countries.
\end{abstract}

Methods: Patients aged 16 years or older starting cART in a clinic participating in a multicohort collaboration spanning 6 continents (International epidemiological Databases to Evaluate AIDS and ART Cohort Collaboration) were eligible. Multilevel linear regression models were adjusted for age, gender, and calendar year; missing CD4 counts were imputed.

Results: In total, 379,865 patients from 9 LIC, 4 LMIC, 4 UMIC, and 6 HIC were included. In LIC, the median CD4 cell count at cART initiation increased by $83 \%$ from 80 to 145 cells $/ \mu \mathrm{L}$ between 2002 and 2009. Corresponding increases in LMIC, UMIC, and HIC were from 87 to 155 cells $/ \mu \mathrm{L}$ ( $76 \%$ increase), 88 to 135 cells $/ \mu \mathrm{L}$ (53\%), and 209 to 274 cells/ $\mu \mathrm{L}$ (31\%). In 2009, compared with LIC, median counts were 13 cells $/ \mu \mathrm{L}$ [95\% confidence interval (CI): -56 to +30 ] lower in LMIC, 22 cells $/ \mu \mathrm{L}(-62$ to +18$)$ lower in UMIC, and 112 cells $/ \mu \mathrm{L}(+75$ to +149$)$ higher in HIC. They were 23 cells $/ \mu \mathrm{L}$ (95\% CI: +18 to +28 cells $/ \mu \mathrm{L}$ ) higher in women than men. Median counts were 88 cells $/ \mu \mathrm{L}(95 \%$ CI: +35 to +141 cells $/ \mu \mathrm{L})$ higher in countries with an estimated national cART coverage $>80 \%$, compared with countries with $<40 \%$ coverage.

Conclusions: Median CD4 cell counts at the start of cART increased 2000-2009 but remained below 200 cells/ $\mu \mathrm{L}$ in LIC and MIC and below 300 cells $/ \mu \mathrm{L}$ in HIC. Earlier start of cART will require substantial efforts and resources globally.

Key Words: antiretroviral therapy, CD4 cell count, sub-Saharan Africa, North America, Carribean, Central and South America, Europe, Asia/Pacific

(J Acquir Immune Defic Syndr 2014;65:e8-e16)

Received for publication February 15, 2013; accepted July 3, 2013.

The authors have no conflicts of interest to disclose.

See Acknowledgments for financial Support and grants.

See Appendix for writing committee.

Supplemental digital content is available for this article. Direct URL citations appear in the printed text and are provided in the HTML and PDF versions of this article on the journal's Web site (www.jaids.com).

Correspondence to: Matthias Egger, Institute of Social \& Preventive Medicine, University of Bern, Finkenhubelweg 11, CH-3012 Bern, Switzerland (e-mail: egger@ispm.unibe.ch).

Copyright (C) 2013 by Lippincott Williams \& Wilkins

\section{INTRODUCTION}

The prognosis of HIV-positive patients has dramatically improved with the advent, in 1996, of combination antiretroviral therapy (cART) ${ }^{1,2}$ Suppressed viral replication allows reconstitution of the immune system: peripheral CD4 cell counts increase rapidly first from redistribution from lymphoid tissues and then gradual by de novo synthesis. ${ }^{3,4}$ Since 2002, the Global Fund for Tuberculosis, AIDS, and Malaria; US President's Emergency Plan for AIDS Relief (PEPFAR); and other funders have sharply increased global cART availability. The World Health Organization (WHO) estimated, by 2010, that 6.6 million of the 15 million who needed cART in low- and middle-income countries had access. ${ }^{5}$

When to initiate cART to maximize the benefit of therapy has been debated for years. ${ }^{6}$ Benefits of early initiation, at high CD4 cell counts, must be balanced against drug toxicities and the potential for drug resistance. Conversely, starting therapy late, as measured clinically or by CD4 count, is associated with poorer prognosis and increased mortality. ${ }^{7}$ A substudy of the Strategies for Management of Antiretroviral Therapy trial showed that delaying cART until the count fell below 250 cells $/ \mu \mathrm{L}$ more than tripled the rate of AIDS or death compared with starting above 350 cells $/ \mu \mathrm{L}^{8}{ }^{8}$ Analyses that combined data from cohort studies also indicated that starting cART above $350 \mathrm{CD} 4$ cells $/ \mu \mathrm{L}$ is beneficial, and some, but not all, showed benefit with a threshold of 500 cells $/ \mu$ L. ${ }^{9-11}$ The START (NCT00821171) and TEMPRANO (NCT00495651) trials will provide further data on the efficacy of early versus late initiation of cART.

However, many patients enter care late. An analysis of treatment programs in 12 countries in sub-Saharan Africa, South America, and Asia showed that while CD4 cell counts at initiation increased from 2001 to 2005/2006, most patients started well below recommended thresholds. ${ }^{12}$ Similarly, an US cohort and a Canada cohort showed that median CD4 cell count at first presentation for HIV care was 317 cells $/ \mu \mathrm{L}$ in 2007: more than half of patients initiated therapy below 350 cells $/ \mu \mathrm{L} .{ }^{13}$ A recent Latin American study reported that the percentage of patients initiating cART late ranged from $56 \%$ in Argentina to $91 \%$ in Honduras. ${ }^{14}$

Early initiation of cART is recognized as having a broader role in HIV prevention. ${ }^{15}$ Already established as a means to prevent mother-to-child transmission (PMTCT), ${ }^{5}$ the HIV Prevention Trials Network 052 trial found that cART reduced heterosexual HIV transmission by $96 \%$ between discordant couples. ${ }^{16}$ Combined with other proven prevention 
tools, immediate or early cART might contribute to achieving the goal of an AIDS-free generation. ${ }^{17}$

We examined trends and determinants of the CD4 cell count at cART initiation in patients starting therapy between 2002 and 2010 in low-, middle-, and high-income countries by combining data from 2 HIV cohort consortia, which together span 6 continents.

\section{METHODS}

\section{Data Sources}

The International epidemiological Databases to Evaluate AIDS (IeDEA) is a global consortium structured through regional centers to pool clinical and epidemiological data on HIV-positive individuals, particularly patients on cART. The 7 regions included in IeDEA are North America, Caribbean/ Central and South America, Asia/Pacific, East Africa, West Africa, Central Africa, and Southern Africa. Regional cohorts of IeDEA have been described in detail elsewhere. ${ }^{18-21}$ The European cohorts of the ART Cohort Collaboration, a network of cohort studies of patients on cART in high-income countries (HIC), were also included. ${ }^{7}$ Pooling of data and their use in collaborative analyses were approved by local ethics committees and institutional review boards. For the present study, regional centers sent de-identified data to the University of Bern, Switzerland, for cleaning and analysis.

\section{Inclusion Criteria and Definitions}

Patients aged 16 years or older at cART initiation were eligible. cART was defined as a regimen of at least 3 antiretroviral drugs, typically from 2 drug classes. Baseline CD4 cell count was defined as the count nearest to the date of cART start with a window of 6 months before to 1 month after starting. CD4 cell counts above 5000 cells $/ \mu \mathrm{L}$ (ie, $>3$ times above the upper reference range in whites ${ }^{22}$ ) were considered invalid and set to missing. Countries were grouped according to the World Bank classification of Gross National Income per Capita 2010 as low-income countries (LIC, US $\$ 1005$ or less per year), lower middle-income countries (LMIC, US\$1006 to 3975 per year), upper middle-income countries (UMIC, US\$3976 to 12,275 per year), and highincome countries (HIC, US\$12,276 or more per year). ${ }^{23}$ Data on national cART coverage for 2009 (based on the WHO 2006 treatment guidelines ${ }^{24}$ ) were obtained from the 2010 progress report on the Global HIV/AIDS response published by $\mathrm{WHO}^{25}$ for LIC and MIC.

\section{Statistical Analyses}

Descriptive analyses were stratified by country, gender, and World Bank country income group. CD4 cell counts at cART start and other baseline characteristics were summarized as medians with interquartile ranges or numbers with percentages. To address the problem of generalizing data from a small sample to an entire country, further analyses were restricted to countries that contributed at least 500 patients with CD4 cell counts from 2 or more sites and had observations after 2007.

Missing CD4 counts were multiply imputed using predictive mean matching and chained equations stratified by gender, age, and country income level. Technical details on the multiple imputation are provided in the Supplemental Digital Content (see http://links.lww.com/QAI/A446). All analyses were performed both for the imputed data and for the complete case dataset. To assess trends and examine individual-level and country-level predictors of median baseline CD4 cell counts, we aggregated the data by sex, age, year, and country. We then fitted 3 types of weighted linear regression models. First, a simple linear regression estimated gender-specific annual changes in median baseline CD4 cell counts by country (model 1). In sensitivity analyses, we weighted individual country data to create a data set that was representative, within each income group, of the number of patients on cART in each country in 2009, as estimated by WHO. ${ }^{5}$ The derivation of the weighting factors is shown in Table S1 (see Supplemental Digital Content, http://links.lww.com/QAI/A446).

Second, a weighted mixed-effects linear regression was used to estimate the median CD4 cell counts at the start of cART in 2009 and to examine the influence of age, sex, country income level, and, in an analysis restricted to LIC and MIC, of national cART coverage (model 2). Age, calendar year, gender, and country income level were entered as fixed effects and country as random effect. The third model included calendar year, gender, and country income level and was used to model median CD4 cell count trends between 2002 and 2010 (model 3). Finally, the proportions of patients starting cART with CD4 cell counts below 50, 100, and 200 cells/ $\mu \mathrm{L}$ were analyzed using generalized linear mixed effects models. Age, calendar year, gender, and country income level were entered as fixed effects and intercept and slope as random effects, by country. Data were analyzed using Stata 12.0 (Stata Corporation, College Station, TX) and R 2.12 (The R Development Core Team, Vienna, Austria).

\section{RESULTS}

\section{Descriptive Analyses}

Data from 492,915 patients aged 16 years or older who started cART in 48 countries were submitted to the data center (Fig. 1). Among 437,230 ART-naive patients with known age, gender, and start date, 309,564 (63\%) had a CD4 cell count at the start of cART. Compared with the 127,666 patients without a CD4 cell count, patients with counts at cART initiation were younger, more likely to be male, and more likely to be from a high-income country. Importantly, those with CD4 cell counts were less likely to have advanced disease (WHO stage III/IV) than patients without CD4 cell counts (see Table S2, Supplemental Digital Content, http://links.lww.com/QAI/ A446). Only 4.6\% (20,217 patients) had an earlier CD4 cell count, 6 months or more before starting ART.

The number of included patients from each country varied from 60 from Japan to 147,029 from Zambia (Table 1). There were 12 countries with up to 500 patients, 23 with 


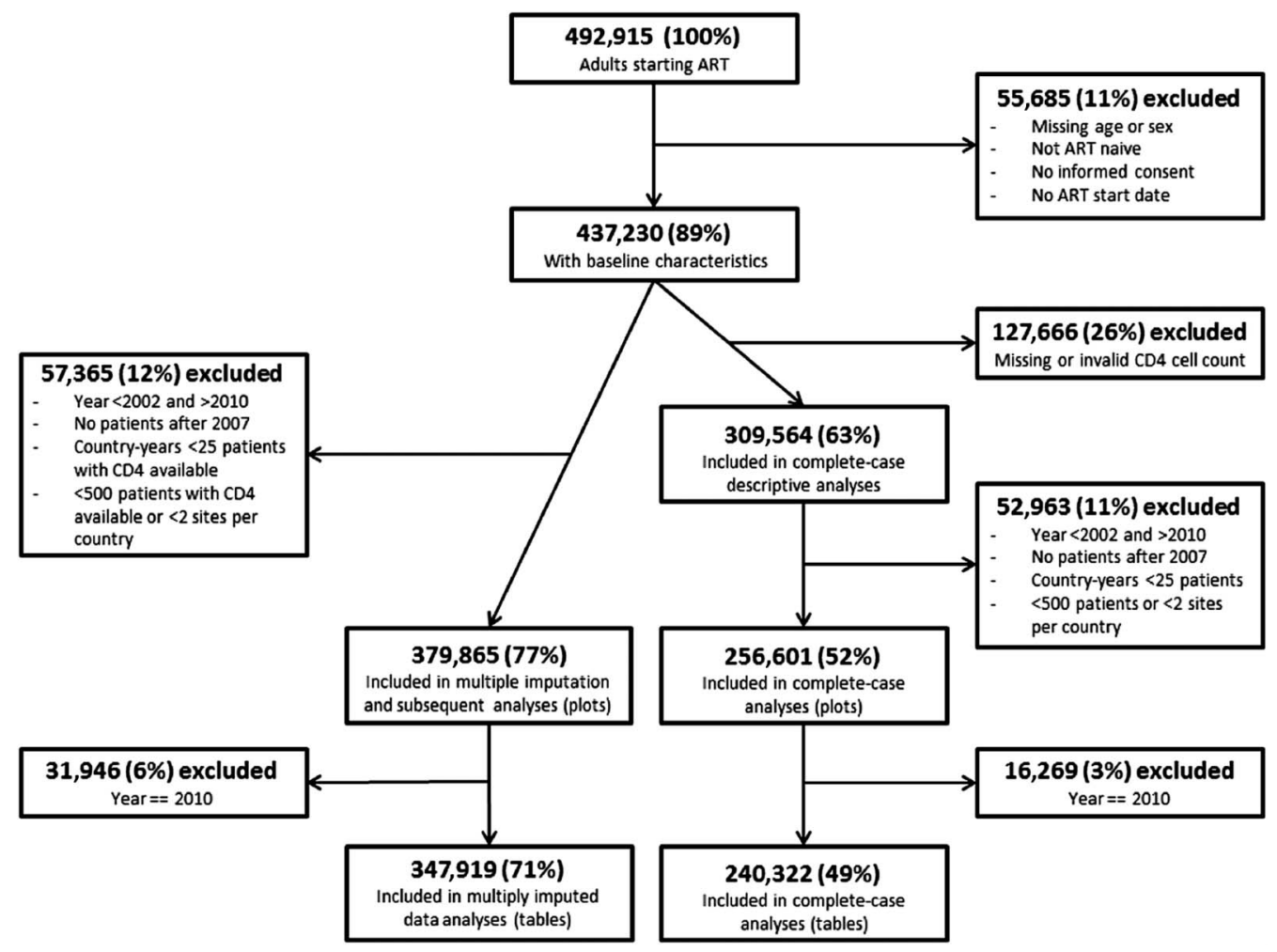

FIGURE 1. Flow chart of patients included and excluded from analyses.

501-5000 patients, 4 with 5001-10,000 patients, 7 with 10,00150,000 , and 2 with more than 50,000 patients (see Figure S1, Supplemental Digital Content, http://links.lww.com/QAI/A446). The percentage of female patients ranged from $4 \%$ in Taiwan to $73 \%$ in Burundi, and median age ranged from 30.9 years in Indonesia to 41.5 years in Nigeria (Table 1). The median year of cART initiation ranged from 2000 in Australia and Italy to 2009 in the Philippines. The median CD4 cell count at cART initiation for the entire study period ranged from 56 cells $/ \mu \mathrm{L}$ in Indonesia to 290 cells $/ \mu \mathrm{L}$ in Australia.

\section{Regression Models}

A total of 379,865 patients from 23 countries were included in the regression models, including 86,390 patients from 9 LIC (23\%), 176,858 from 4 LMIC (47\%), 82,152 from 4 UMIC (22\%), and 34,465 from 6 HIC (9\%). The Democratic Republic of the Congo, Kenya, Malawi, and Mali were overrepresented when compared with the WHO estimates of the number of patients on cART in the LIC included in our study. In contrast, Tanzania and Zimbabwe were underrepresented. The group of LMIC countries was dominated by Zambia and that of UMIC countries by South Africa. Among HIC, France contributed almost half of all patients, whereas the United States and Italy were underrepresented (see Table S1, Supplemental Digital Content, http://links.lww.com/QAI/A446).

The annual increase in median CD4 cell counts at the start of cART initiation from 2002 to 2009, estimated through linear regression (model 1), varied within and across World
Bank country groups and tended to be greater among women than men (Table 2). Among LIC, the annual change in median CD4 cell counts ranged from -14 cells $/ \mu \mathrm{L}[95 \%$ confidence interval (CI): -37 to +9 cells $/ \mu \mathrm{L}]$ among women in the Democratic Republic of the Congo to +32 cells/ $\mu \mathrm{L}(95 \% \mathrm{CI}:+22$ to +42 cells $/ \mu \mathrm{L}$ ) among Rwandan women. For LMIC, the corresponding range was from -2 cells $/ \mu \mathrm{L}(95 \% \mathrm{CI}$ : -14 to +9 cells $/ \mu \mathrm{L})$ among Nigerian men to +13 cells $/ \mu \mathrm{L}(95 \%$ CI: +8 to +19 cells $/ \mu \mathrm{L}$ ) among women in Côte d'Ivoire. In $\mathrm{UMIC}$, the range was from -1 cells $/ \mu \mathrm{L}(-17$ to +15 cells $/ \mu \mathrm{L})$ in Botswana men to +15 cells $/ \mu \mathrm{L}$ ( $95 \%$ CI: 0 to +29 cells $/ \mu \mathrm{L}$ ) among Brazilian men. Finally, in HIC, the range was from -3 cells $/ \mu \mathrm{L}(95 \% \mathrm{CI}:-12$ to +7 cells $/ \mu \mathrm{L})$ in Australian men to +16 cells $/ \mu \mathrm{L}(95 \%$ CI: +12 to +20 cells $/ \mu \mathrm{L})$ in Canadian men. Crude (unweighted) and weighted pooled estimates of annual increases in CD4 cell count at cART initiation by country group were generally similar (Table 2). Also, results were similar in the complete case analysis (see Table S3, Supplemental Digital Content, http://links.lww.com/QAI/A446).

Table 3 shows estimated median CD4 cell counts at the start of cART in 2009 by age, gender, and country income level, as estimated from the mixed effects linear regression (model 2). Median CD4 cell counts were higher in women compared with men (difference +23 cells $/ \mu \mathrm{L}, 95 \% \mathrm{CI}$ : +18 to +28 cells $/ \mu \mathrm{L}$ ) and lower for patients aged 30 to 40 years or younger (difference -16 cells $/ \mu \mathrm{L}, 95 \% \mathrm{CI}:-21$ to -10 cells/ $\mu \mathrm{L}$ ) and 40 to 50 years or younger (difference -17 cells $/ \mu \mathrm{L}$, $95 \% \mathrm{CI}:-24$ to -10 cells $/ \mu \mathrm{L}$ ) compared with those younger than 30 years. Median counts were similar in LIC, LMIC, and UMIC but were higher in HIC (difference compared with low- 
TABLE 1. Characteristics of Patients Starting CART by Country and World Bank Income Groups

\begin{tabular}{|c|c|c|c|c|c|c|c|c|}
\hline \multirow[b]{2}{*}{ Country } & \multicolumn{2}{|c|}{ No. Patients } & \multicolumn{2}{|c|}{ Median Age in Years (IQR) } & \multicolumn{2}{|c|}{$\begin{array}{l}\text { Median Calendar Year of Starting } \\
\text { cART (IQR) }\end{array}$} & \multicolumn{2}{|c|}{$\begin{array}{c}\text { Median CD4 Cell Count at } \\
\text { Start of cART in Cells } / \mu \mathrm{L} \\
\text { (IQR) }\end{array}$} \\
\hline & Women & Men & Women & Men & Women & Men & Women & Men \\
\hline Benin & 413 & 298 & 33.8 & 40.1 & 2005 & 2005 & 119 & 90 \\
\hline Burkina Faso & 822 & 348 & 35.7 & 41.3 & 2007 & 2006 & 182 & 137.5 \\
\hline Burundi & 332 & 139 & 36.4 & 43.0 & 2009 & 2009 & 209.5 & 157 \\
\hline Gambia & 140 & 77 & 37.4 & 45.0 & 2006 & 2006 & 160 & 130 \\
\hline Haiti & 780 & 668 & 38.0 & 40.0 & 2004 & 2004 & 115.5 & 92.5 \\
\hline Kenya & 19,454 & 10,571 & 35.2 & 39.6 & 2007 & 2006 & 135 & 109 \\
\hline Malawi & 4337 & 3365 & 33.3 & 37.2 & 2008 & 2008 & 150 & 122 \\
\hline Mali & 1020 & 650 & 32.7 & 40.2 & 2006 & 2006 & 134 & 101 \\
\hline Zimbabwe & 3112 & 1388 & 37.1 & 39.7 & 2009 & 2009 & 133 & 96 \\
\hline Overall & 40,526 & 22,714 & $35.1(29-41)$ & $39.4(33-46)$ & 2007 (2006-2008) & 2007 (2006-2008) & $139(65-213)$ & $113(40-186)$ \\
\hline \multicolumn{9}{|l|}{ Lower middle-income } \\
\hline Cameroon & 1821 & 829 & 33.9 & 39.3 & 2009 & 2009 & 158 & 139 \\
\hline Côte d'Ivoire & 8531 & 4857 & 34.5 & 41.1 & 2006 & 2005 & 156 & 125 \\
\hline Honduras & 101 & 159 & 35.0 & 38.0 & 2005 & 2005 & 120 & 98 \\
\hline India & 91 & 364 & 31.9 & 34.1 & 2004 & 2003 & 177 & 129.5 \\
\hline Indonesia & 92 & 227 & 29.1 & 31.4 & 2008 & 2008 & 89.5 & 45 \\
\hline Nigeria & 4728 & 2678 & 41.2 & 41.3 & 2006 & 2006 & 162 & 127 \\
\hline Philippines & 27 & 234 & 39.3 & 30.5 & 2008 & 2009 & 186 & 180 \\
\hline Senegal & 183 & 126 & 35.4 & 42.0 & 2004 & 2004.5 & 122 & 97.5 \\
\hline Malaysia & 111 & 380 & 34.1 & 36.2 & 2007 & 2008 & 159 & 113 \\
\hline Mexico & 49 & 349 & 35.0 & 35.0 & 2004 & 2004 & 131 & 84 \\
\hline Peru & 208 & 495 & 32.0 & 35.0 & 2005 & 2005 & 85.5 & 74 \\
\hline South Africa & 32,920 & 21,673 & 33.6 & 39.0 & 2007 & 2007 & 124 & 111 \\
\hline Thailand & 731 & 907 & 35.7 & 36.3 & 2007 & 2008 & 95 & 89 \\
\hline Overall & 35,327 & 26,182 & $33.7(28-39)$ & $38.5(32-45)$ & 2007 (2006-2008) & 2006 (2004-2008) & $124(60-188)$ & $111(42-180)$ \\
\hline \multicolumn{9}{|l|}{ High-income } \\
\hline Australia & 74 & 1261 & 33.7 & 39.1 & 2001 & 1999 & 280 & 290 \\
\hline Canada & 850 & 3651 & 36.0 & 41.0 & 2002 & 2002 & 210 & 220 \\
\hline France & 10,023 & 20,739 & 34.3 & 38.8 & 2003 & 2001 & 237 & 233 \\
\hline Germany & 269 & 955 & 33.9 & 38.5 & 2004 & 2002 & 177 & 173 \\
\hline Italy & 915 & 2312 & 35.4 & 37.6 & 2000 & 2000 & 265 & 244 \\
\hline Japan & 4 & 56 & 46.1 & 38.1 & 2006 & 2007 & 236 & 253.5 \\
\hline The Netherlands & 1617 & 5125 & 32.4 & 39.4 & 2003 & 2002 & 210 & 189 \\
\hline Singapore & 19 & 83 & 33.9 & 41.4 & 2004 & 2003 & 134 & 57 \\
\hline South Korea & 10 & 182 & 41.2 & 38.0 & 2003.5 & 2006 & 123 & 222.5 \\
\hline Spain & 2596 & 8406 & 34.0 & 36.8 & 2002 & 2003 & 224 & 201 \\
\hline
\end{tabular}


TABLE 1. (Continued) Characteristics of Patients Starting CART by Country and World Bank Income Groups

\begin{tabular}{|c|c|c|c|c|c|c|c|c|}
\hline \multirow[b]{2}{*}{ Country } & \multicolumn{2}{|c|}{ No. Patients } & \multicolumn{2}{|c|}{ Median Age in Years (IQR) } & \multicolumn{2}{|c|}{$\begin{array}{c}\text { Median Calendar Year of Starting } \\
\text { cART (IQR) }\end{array}$} & \multicolumn{2}{|c|}{$\begin{array}{l}\text { Median CD4 Cell Count at } \\
\text { Start of cART in Cells } / \mu \mathrm{L} \\
\text { (IQR) }\end{array}$} \\
\hline & Women & Men & Women & Men & Women & Men & Women & Men \\
\hline Taiwan & 8 & 186 & 32.2 & 32.9 & 2001.5 & 2003 & 132 & 225 \\
\hline UK & 369 & 1016 & 34.3 & 36.9 & 2003 & 2002 & 158 & 206 \\
\hline USA & 3362 & 8991 & 39.0 & 40.0 & 2003 & 2003 & 241.5 & 215 \\
\hline
\end{tabular}

Results from complete case descriptive analyses based on 309,564 patients.

IQR, interquartile ranges.

income countries +112 cells $/ \mu \mathrm{L}, 95 \% \mathrm{CI}:+75$ to +149 cells $/ \mu \mathrm{L})$. In the analysis restricted to LIC and MIC, those with cART coverage of $80 \%$ or greater (Botswana, Brazil, Cambodia, Rwanda, and Zambia) had substantially higher CD4 cell counts at cART initiation (difference +88 cells $/ \mu \mathrm{L} ; 95 \% \mathrm{CI}$ : +35 to +141 cells $/ \mu \mathrm{L}$ ) than countries with a coverage below $40 \%$ (Côte d'Ivoire, Democratic Republic of the Congo, Indonesia, Nigeria, and Malaysia). Results were again similar in the complete case analysis (see Table S4, Supplemental Digital Content, http://links.lww.com/QAI/A446).

Figure 2 shows trajectories of median CD4 cell counts at cART initiation and the percentage of patients starting cART below 200 cells $/ \mu \mathrm{L}$ and below 100 cells $/ \mu \mathrm{L}$, by country income group and gender, estimated by model 3. In LIC, median CD4 cell count at the start of cART increased by $91 \%$ in women from 2002 to 2009 (from 82 to 157 cells $/ \mu \mathrm{L}$ ) and by $62 \%$ (from 79 to 127 cells/ $\mu \mathrm{L}$ ) in men. Corresponding increases for LMIC were from 83 to 166 cells $/ \mu \mathrm{L}$ in women (a $102 \%$ increase) and from 97 to 138 cells $/ \mu \mathrm{L}$ in men (a $42 \%$ increase). The increases in UMIC were from 86 to 141 cells $/ \mu \mathrm{L}$ in women (a $63 \%$ increase) and from 91 to 125 cells $/ \mu \mathrm{L}$ in men (a 36\% increase). Finally, in HIC, median CD4 cell counts at cART initiation increased by $26 \%$ (from 211 to 266 cells $/ \mu \mathrm{L}$ ) in women and by $34 \%$ (from 208 to 280 cells/ $\mu \mathrm{L}$ ) in men.

In LIC, the percentage of patients starting cART below 200 cells $/ \mu \mathrm{L}$ declined from $85 \%$ in 2002 to $81 \%$ in 2009 in women and from $88 \%$ to $70 \%$ in men. Corresponding figures for LMIC were from $78 \%$ to $59 \%$ in women and from $79 \%$ to $67 \%$ in men and for UMIC from $86 \%$ to $65 \%$ in women and from $78 \%$ to $71 \%$ in men. In HIC, the decline was from $46 \%$ to $31 \%$ in women and from $49 \%$ to $35 \%$ in men. For threshold below 100 cells/ $\mu \mathrm{L}$, the declines were from $50 \%$ to $28 \%$ in women and from $57 \%$ to $36 \%$ in men in LIC, from $47 \%$ to $27 \%$ in women and from $51 \%$ to $36 \%$ in men in LMIC, from $54 \%$ to $31 \%$ in women and from $49 \%$ to $40 \%$ in men in UMIC, and from $22 \%$ to $15 \%$ in women and from $27 \%$ to $17 \%$ in men in HIC. Trends were similar in the complete case analysis (see Figure S2, Supplemental Digital Content, http://links.lww.com/QAI/A446).

\section{DISCUSSION}

This global analysis of CD4 cell counts at cART initiation between 2002 and 2010 was conducted in 2 HIV cohort collaborations, which together span 6 continents. ${ }^{7,18-21}$ We found that median CD4 cell counts at cART initiation were substantially higher in HIC, with only small differences between LIC and MIC. Median CD4 cell counts at the start of cART increased over the study period in most countries. These increases were greater in LIC and MIC than in HIC, and greater in women than in men. Among LIC and MIC, median CD4 cell counts at the start of cART were substantially higher in the few countries with national cART coverage of $80 \%$ or above.

In LIC and MIC, the median CD4 cell count remained well below 200 cells/ $\mu \mathrm{L}$ between 2002 and 2009, despite the 2001 WHO recommendation to start when the CD4 gets near or falls below 200 cells $/ \mu \mathrm{L}$ or, in persons with advanced clinical disease (WHO stage IV), irrespective of the CD4 cell count. ${ }^{26}$ Following a 2006 recommendation to consider treatment at CD4 cell counts below 350 cells/ $\mu \mathrm{L}$ for patients in WHO stage III, WHO indicated in 2009 that cART should be initiated at 350 cells $/ \mu \mathrm{L}$ irrespective of clinical symptoms. ${ }^{27}$ National guidelines in resource-limited settings generally echoed WHO guidelines, ${ }^{28}$ whereas HIC have more rapidly increased the CD4 cell count threshold for initiation. Of note, North American guidelines recently converged in their recommendation that cART should be offered to all HIV-positive individuals, irrespective of the CD4 cell count. ${ }^{29,30}$

A substantial rise in HIV testing in many countries, supported by Global Fund for Tuberculosis, AIDS and Malaria, PEPFAR, national or state/provincial level governments, and other donors, may have contributed to increasing CD4 cell counts at the start of cART. A monitoring and evaluation analysis of PEPFAR-supported HIV care clinics in 8 sub-Saharan African countries found that $\mathrm{CD} 4$ cell counts at cART initiation increased with HIV testing coverage in the region. ${ }^{31}$ In sub-Saharan Africa, PEPFAR supported over 140 million testing and counseling sessions between 2004 and 2011, with the number of sessions increasing from 1.9 million in 2004 to over 40 million in 2011. ${ }^{32}$ Two Demographic and Health Surveys from 7 PEPFAR countries conducted between 2003 and 2010 showed a dramatic increase in population level coverage of HIV testing and counseling. ${ }^{32}$ In Kenya, for example, the percentage of men reporting testing in the last 12 months increased from $7.5 \%$ to $22.7 \%$. The corresponding increase was even greater in women, from $6.7 \%$ to $29.3 \%$. Similarly, in Lesotho, testing increased from $6.3 \%$ to $42.0 \%$ in women and from $4.8 \%$ to $24.0 \%$ in men. Provider- 
TABLE 2. Annual Change Between 2002 and 2009 in Median CD4 Cell Count at the Start of CART in LIC, LMIC, UMIC, and HIC, by Gender

\begin{tabular}{|c|c|c|}
\hline Country & $\begin{array}{c}\text { Women } \\
\text { CD4 Cells } / \mu \mathrm{L} \\
(95 \% \text { CI })\end{array}$ & $\begin{array}{c}\text { Men } \\
\text { CD4 Cells } / \mu \mathrm{L} \\
(95 \% \text { CI })\end{array}$ \\
\hline \multicolumn{3}{|l|}{ Low-income } \\
\hline Benin & $+8(-15$ to +31$)$ & $+4(-11$ to +19$)$ \\
\hline DR Congo & $-14(-37$ to +9$)$ & $+6(-11$ to +22$)$ \\
\hline Kenya & $+15(+13$ to +18$)$ & $+11(+8$ to +14$)$ \\
\hline Malawi & $+9(+2$ to +15$)$ & $+12(+4$ to +21$)$ \\
\hline Mali & $+12(-2$ to +27$)$ & $+4(-1$ to +10$)$ \\
\hline Rwanda & $+32(+22$ to +42$)$ & $+31(+12$ to +51$)$ \\
\hline Tanzania & $+7(-1$ to +14$)$ & $+2(-4$ to +8$)$ \\
\hline Uganda & $+23(+11$ to +35$)$ & $+16(+1$ to +31$)$ \\
\hline Zimbabwe & $+8(+1$ to +15$)$ & $+5(-1$ to +11$)$ \\
\hline \multicolumn{3}{|l|}{ Pooled } \\
\hline Crude & $+12(+6$ to +17$)$ & $+11(+7$ to +15$)$ \\
\hline Weighted* & $+11(+4$ to +17$)$ & $+9(+4$ to +14$)$ \\
\hline \multicolumn{3}{|c|}{ Lower middle-income } \\
\hline Cameroon & $+10(-4$ to +24$)$ & $+13(-4$ to +31$)$ \\
\hline Côte d'Ivoire & $+13(+8$ to +19$)$ & $+10(0$ to +20$)$ \\
\hline Nigeria & $+4(-13$ to +21$)$ & $-2(-14$ to +9$)$ \\
\hline Zambia & $+11(+9$ to +13$)$ & $+8(+4$ to +11$)$ \\
\hline \multicolumn{3}{|l|}{ Pooled } \\
\hline Crude & $+9(+6$ to +12$)$ & $+7(+4$ to +10$)$ \\
\hline Weighted* & $+6(+1$ to +11$)$ & $+5(+1$ to +9$)$ \\
\hline \multicolumn{3}{|c|}{ Upper middle-income } \\
\hline Botswana & $+9(-4$ to +23$)$ & $-1(-17$ to +15$)$ \\
\hline Brazil & $+8(-8$ to +24$)$ & $+15(0$ to +29$)$ \\
\hline South Africa & $+9(+8$ to +11$)$ & $+4(+1$ to +7$)$ \\
\hline Thailand & $+10(+2$ to +17$)$ & $+6(-6$ to +18$)$ \\
\hline \multicolumn{3}{|l|}{ Pooled } \\
\hline Crude & $+9(+6$ to +11$)$ & $+4(+1$ to +7$)$ \\
\hline Weighted* & $+7(+1$ to +13$)$ & $+6(-1$ to +13$)$ \\
\hline \multicolumn{3}{|l|}{ High-income } \\
\hline Australia & $+10(-18$ to +38$)$ & $-3(-12$ to +7$)$ \\
\hline Canada & $+7(-1$ to +15$)$ & $+16(+12$ to +20$)$ \\
\hline France & $+11(+8$ to +13$)$ & $+9(+3$ to +15$)$ \\
\hline Italy & $+4(-3$ to +11$)$ & $+6(-3$ to +14$)$ \\
\hline Spain & $+3(-1$ to +7$)$ & $+6(+2$ to +10$)$ \\
\hline USA & $+9(+2$ to +16$)$ & $+13(+6$ to +20$)$ \\
\hline \multicolumn{3}{|l|}{ Pooled } \\
\hline Crude & $+9(+6$ to +11$)$ & $+9(+6$ to +12$)$ \\
\hline Weighted* & $+7(+4$ to +11$)$ & $+9(+6$ to +13$)$ \\
\hline
\end{tabular}

Results from linear regression (model 1) based on 347,919 patients, with missing values imputed using multiple imputation.

*Weighted by the number of patients on cART in the respective country, as estimated by WHO. ${ }^{5}$

initiated testing and counseling may not, however, be sufficient to prevent late HIV diagnosis. Uganda adopted provider-initiated HIV testing in the health care setting in 2005, but in a recent randomized controlled trial, half of HIV-positive patients screened had CD4 cell counts below or equal to 250 cells $/ \mu \mathrm{L} .^{33}$

The steeper increase of HIV testing coverage among women compared with men may be explained by scale-up of programs to PMTCT. More frequent testing leads to earlier
TABLE 3. Individual-Level and Country-Level Predictors of the Median CD4 Cell Count at the Start of CART in 2009

\begin{tabular}{lc}
\hline Variable & Median CD4 Cell Count (Cells/ $\boldsymbol{\mu L})$ \\
\hline Sex & 164 (intercept, 140 to 189$)$ \\
Male & 23 (18 to 28$)$ \\
Female & 164 (intercept, 140 to 189$)$ \\
Income group & $-13(-56$ to 30$)$ \\
Low & $-22(-62$ to 18$)$ \\
Lower middle & $112(75$ to 149$)$ \\
Upper middle & \\
High & 164 (intercept, 140 to 189$)$ \\
Age group (yrs) & $-16(-21$ to -10$)$ \\
$<30$ & $-17(-24$ to -10$)$ \\
30 to $<40$ & $-3(-12$ to 6$)$ \\
40 to $<50$ & \\
$\geq 50$ & 144 (intercept, 103 to 185$)$ \\
National cART coverage (\%)* & $10(-38$ to 57$)$ \\
$<40$ & $-6(-58$ to 46$)$ \\
40 to $<60$ & $88(35$ to 141$)$ \\
60 to $<80$ &
\end{tabular}

Results from mixed effects linear regression (model 2) based on 55,007 patients starting cART in 2009 , missing values imputed using multiple imputation. Intercepts and coefficients ( $95 \%$ confidence intervals) are shown. All models include calendar year, age, gender, and income group. The intercept of 164 cells $/ \mu \mathrm{L}$ corresponds to men in low-income countries.

* Separate analysis based on 52,482 patients starting cART in 2009 in low-income and middle-income countries (model 2). The intercept of 144 cells $/ \mu \mathrm{L}$ corresponds to men in low-income countries. Estimates of national cART coverage in 2009, based on WHO 2006 guidelines were as follows ${ }^{25}$ : Benin 72\%, Democratic Republic of the Congo $26 \%$, Kenya $65 \%$, Malawi $63 \%$, Mali $65 \%$, Rwanda $>95 \%$, Tanzania $44 \%$, Uganda 53\%, Zimbabwe 49\%, Cameroon 41\%, Côte d'Ivoire 39\%, Nigeria 31\%, Zambia $85 \%$, Botswana $>95 \%$, Brazil $80 \%$, South Africa $56 \%$, and Thailand $76 \%$.

diagnosis and then earlier initiation of cART in eligible women. The scale-up of PMTCT could thus also account for the greater increases of CD4 cell counts at the start of cART in women than men observed in the present study. A review of national program data for 2004 to 2005 showed that the scale-up of PMTCT had gained momentum in many countries and that provider-initiated (opt-out) HIV testing had become nearly universal in some regions (eg, in East and Southern Africa) but not in others (eg, in West Africa). ${ }^{34}$ A systematic review and meta-analysis of 44 studies of pregnant women who attended PMTCT programs in sub-Saharan Africa showed that uptake at antenatal care services was $94 \%$ for opt-out testing compared with $58 \%$ for opt-in testing. ${ }^{35} \mathrm{Cov}$ erage with any type of antiretroviral prophylaxis was $70 \%$, and $62 \%$ of pregnant women eligible for cART received treatment. ${ }^{35}$ Similarly, a meta-analysis of 6 studies that reported on numbers of adults followed up between HIV diagnosis and start of cART showed that of every 100 patients with a positive HIV test, 72 had a CD4 cell count measured, 40 were eligible for cART, and 25 started cART. Of note, men were more likely to be lost to program and less likely to start cART than women. ${ }^{36}$

Our study has several limitations. We could only examine information up to 2010 because more recent data were not yet available from many sites participating in the IeDEA and ART cohort collaborations. CD4 cell counts at the 


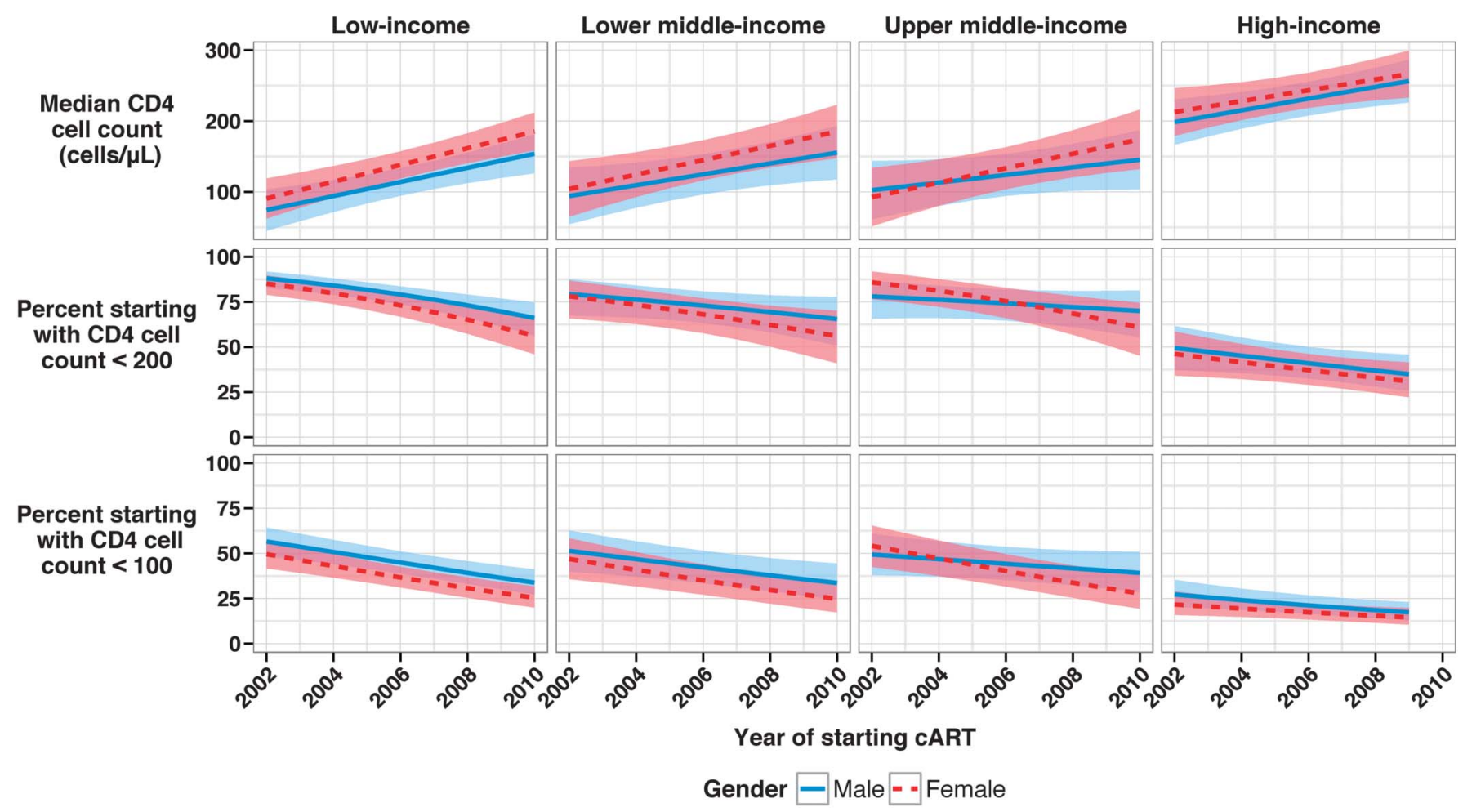

FIGURE 2. Trends of median CD4 cell counts at the start of CART (upper panel) and in proportions of men and women starting cART below 200 cells/ $\mu \mathrm{L}$ (middle panel) or below 100 cells/ $\mu \mathrm{L}$ (lower panel) in low-, middle-, and high-income countries, 20022010. The shaded areas represent the $95 \% \mathrm{Cl}$ for each year. Results from mixed effects linear regression (model 3 ) are based on 379,865 patients; missing values imputed using multiple imputation.

start of cART were missing in approximately 1 quarter of patients, who were more likely to be from LIC and MIC and in a more advanced stage of disease than patients with measured CD4 cell counts. It is thus likely that our estimates of median CD4 cell counts at cART initiation are biased upward for these countries. Data from some countries were limited to a small number of patients from a single clinic. We decided to include these in descriptive analyses, but because the data are probably not representative of all patients on cART in those countries, we excluded them from analyses of time trends and predictors of CD4 cell count at the start of cART. In sensitivity analyses, we weighted individual country data, with the aim of creating a data set that was representative, within each income group, of the number of patients on cART in each country, as estimated by WHO. ${ }^{5}$ Some of the data included in these sensitivity analyses may, however, not be representative of all patients on CART in the country. In particular, the clinics from LIC and MIC participating in IeDEA are mainly urban and capture data in electronic databases, indicating a higher level of resources. They may more closely reflect best practice in urban settings than in the country as a whole. Nevertheless, our study is a unique source of information on trends and determinants of the CD4 cell count in adult patients starting cART across the globe.

In conclusion, our results illustrate the enormous challenges that lie ahead. Despite the massive scale up of cART in LIC, from 300,000 patients on cART in 2002 to 6.6 million by the end of 2010, the increases in median CD4 cell count at the start of cART during this period have been modest. In 2009, most patients in LIC and MIC and many patients in HIC started cART with CD4 cell counts below 200 cells $/ \mu \mathrm{L}$, which means that they were already at high risk of complications and had spent years at high risk of HIV transmission. Substantial efforts and resources are needed to achieve earlier implementation of cART globally. Finally, continued monitoring of the CD4 cell count at which HIVpositive patients start cART in LIC, middle-income countries, and $\mathrm{HIC}$ is needed to evaluate the results of these efforts.

\section{ACKNOWLEDGMENTS}

The IeDEA and ART cohort collaborations are grateful to all patients, care givers, and data managers involved in the participating cohorts and treatment programs.

The African regions of the International epidemiological Databases to Evaluate AIDS (IeDEA) are supported by the National Cancer Institute (NCI), the Eunice Kennedy Shriver National Institute of Child Health and Human Development, and the National Institute of Allergy And Infectious Diseases (NIAID) as part of IeDEA (Grants 5U01-AI069919-04, 5U01-AI069924-05, 1U01-AI069927, U01-AI069911-01, 5U01-AI096299). The Caribbean, Central and South America network of IeDEA is supported by NIAID Grant 5U01-AI69923-06. The North American AIDS Cohort Collaboration on Research and Design of IeDEA is supported by Grants U01-AI069918, U10-AA13566, U01- 
AI31834, U01-AI34989, U01-AI34993, U01-AI34994, U01AI35004, U01-AI35039, U01-AI35040, U01-AI35041, U01AI35042, U01-AI35043, U01-AI37613, U01-AI37984, U01AI38855, U01-AI38858, U01-AI42590, U01-AI68634, U01AI68636, U01-HD32632, U10-EY08057, U10-EY08052, U10-EY08067, UL1-RR024131, UL1-RR024131, M01-RR00052, M01-RR00071, M01-RR00079, M01-RR00083, M01RR00722, M01-RR025747, P30-AI27757, P30-AI27767, P30-AI27763, P30-AI50410, P30-AI54999, R01-DA04334, R01-DA12568, R01-DA11602, R01-AA16893, R24AI067039, Z01-CP010176, AHQ290-01-0012, N02CP55504, AI-69432, AI-69434, K01-AI071725, K23-AI610320, K23-EY013707, K24-DA00432, K01AI093197, U10-AA13566, R01-AG029154, and K23 AG024896 from the National Institutes of Health; contract CDC200-2006-18797 from the Centers for Disease Control and Prevention; Grants TGF-96118, HCP-97105, CBR-86906, CBR-94036, KRS-86251, and 169621 from the Canadian Institutes of Health Research; the Canadian HIV Trials Network, project 24; and the Government of British Columbia. The TREAT Asia HIV Observational Database, TREAT Asia Studies to Evaluate Resistance, and the Australian HIV Observational Database are initiatives of TREAT Asia, a program of amfAR, The Foundation for AIDS Research, with support from the Dutch Ministry of Foreign Affairs through a partnership with Stichting Aids Fonds, and the US National Institutes of Health's NIAID, Eunice Kennedy Shriver National Institute of Child Health and Human Development, and NCI, as part of IeDEA (U01AI069907). Queen Elizabeth Hospital and the Integrated Treatment Center received additional support from the Hong Kong Council for AIDS Trust Fund. The Kirby Institute is funded by the Australian Government Department of Health and Ageing and is affiliated with the Faculty of Medicine, The University of New South Wales. The ART Cohort Collaboration is supported by UK Medical Research Council and the Department for International Development (DFID), (grants G0700820 and MR/J002380/1). The content of this publication is solely the responsibility of the authors and does not represent the official views of any of the institutions and funders mentioned.

\section{REFERENCES}

1. Egger M, Hirschel B, Francioli P, et al. Impact of new antiretroviral combination therapies in HIV infected patients in Switzerland: prospective multicentre study. BMJ. 1997;315:1194-1199.

2. Palella FJ, Delaney KM, Moorman AC, et al. Declining morbidity and mortality among patients with advanced human immunodeficiency virus infection. N Engl J Med. 1998;338:853-860.

3. Nash D, Katyal M, Brinkhof MW, et al. Long-term immunologic response to antiretroviral therapy in low-income countries: a collaborative analysis of prospective studies. AIDS. 2008;22:2291-2302.

4. Moore RD, Keruly JC. CD4+ cell count 6 years after commencement of highly active antiretroviral therapy in persons with sustained virologic suppression. Clin Infect Dis. 2007;44:441-446.

5. World Health Organization; UNAIDS; UNICEF. Global HIV/AIDS Response: Epidemic Update and Health Sector Progress Towards Universal Access: Progress Report 2011. Geneva, Switzerland: WHO; 2011.

6. Phillips AN, Gazzard BG, Clumeck N, et al. When should antiretroviral therapy for HIV be started? BMJ. 2007;334:76-78.

7. Egger M, May M, Chene G, et al. Prognosis of HIV-1-infected patients starting highly active antiretroviral therapy: a collaborative analysis of prospective studies. Lancet. 2002;360:119-129.
8. Emery S, Neuhaus JA, Phillips AN, et al. Major clinical outcomes in antiretroviral therapy (ART)-naive participants and in those not receiving ART at baseline in the SMART study. J Infect Dis. 2008;197:1133-1144.

9. Kitahata MM, Gange SJ, Abraham AG, et al. Effect of early versus deferred antiretroviral therapy for HIV on survival. $N$ Engl $J$ Med. 2009;360:1815-1826.

10. Sterne JA, May M, Costagliola D, et al. Timing of initiation of antiretroviral therapy in AIDS-free HIV-1-infected patients: a collaborative analysis of 18 HIV cohort studies. Lancet. 2009;373:1352-1363.

11. HIV-CAUSAL Collaboration; Cain LE, Logan R, et al. When to initiate combined antiretroviral therapy to reduce mortality and AIDS-defining illness in HIV-infected persons in developed countries: an observational study. Ann Intern Med. 2011;154:509-515.

12. Keiser O, Anastos K, Schechter M, et al. Antiretroviral therapy in resource-limited settings 1996 to 2006: patient characteristics, treatment regimens and monitoring in sub-Saharan Africa, Asia and Latin America. Trop Med Int Health. 2008;13:870-879.

13. Althoff KN, Gange SJ, Klein MB, et al. Late presentation for human immunodeficiency virus care in the United States and Canada. Clin Infect Dis. 2010;50:1512-1520.

14. Crabtree-Ramirez B, Caro-Vega Y, Shepherd BE, et al. Cross-sectional analysis of late HAART initiation in Latin America and the Caribbean: late testers and late presenters. PLoS One. 2011;6:e20272.

15. HIV Modelling Consortium Treatment as Prevention Editorial Writing Group. HIV treatment as prevention: models, data, and questionstowards evidence-based decision-making. PLoS Med. 2012;9:e1001259.

16. Cohen MS, Chen YQ, McCauley M, et al. Prevention of HIV-1 infection with early antiretroviral therapy. $N$ Engl J Med. 2011;365:493-505.

17. Fauci AS, Folkers GK. Toward an AIDS-free generation. JAMA. 2012; 308:343-344.

18. Egger M, Ekouevi DK, Williams C, et al. Cohort profile: the International epidemiological Databases to Evaluate AIDS (IeDEA) in sub-Saharan Africa. Int J Epidemiol. 2012;41:1256-1264.

19. Gange SJ, Kitahata MM, Saag MS, et al. Cohort profile: the North American AIDS Cohort Collaboration on Research and Design (NAACCORD). Int J Epidemiol. 2007;36:294-301.

20. McGowan CC, Cahn P, Gotuzzo E, et al. Cohort profile: Caribbean, Central and South America Network for HIV research (CCASAnet) collaboration within the International Epidemiologic Databases to Evaluate AIDS (IeDEA) programme. Int $J$ Epidemiol. 2007;36:969-976.

21. Zhou J, Kumarasamy N, Ditangco R, et al. The TREAT Asia HIV Observational Database: baseline and retrospective data. J Acquir Immune Defic Syndr. 2005;38:174-179.

22. Bofill M, Janossy G, Lee CA, et al. Laboratory control values for CD4 and CD8 T lymphocytes. Implications for HIV-1 diagnosis. Clin Exp Immunol. 1992;88:243-252.

23. The World Bank. How we classify countries. Available at: http://data. worldbank.org/about/country-classifications. Accessed June 15, 2013.

24. World Health Organization. Antiretroviral Therapy for HIV Infection in Adults and Adolescents in Resource-Limited Settings: Towards Universal Access. Recommendations for a Public Health Approach. Geneva, Switzerland: World Health Organization; 2006.

25. World Health Organization. Towards Universal Access. Scaling up Priority HIV/AIDS Interventions in the Health Sector. Progress Report 2010. Geneva, Switzerland: WHO; 2010.

26. World Health Organization. Scaling up Antiretroviral Therapy in Resource-Limited Settings. Guidelines for a Public Health Approach. Geneva, Switzerland: World Health Organization; 2002.

27. World Health Organization. Antiretroviral Therapy for HIV Infection in Adults and Adolescents: Recommendations for a Public Health Approach. 2010 Revision. Geneva, Switzerland: World Health Organization; 2010.

28. Beck EJ, Vitoria M, Mandalia S, et al. National adult antiretroviral therapy guidelines in resource-limited countries: concordance with 2003 WHO guidelines? AIDS. 2006;20:1497-1502.

29. Panel on Antiretroviral Guidelines for Adult and Adolescents. Guidelines for the Use of Antiretroviral Agents in HIV-1-Infected Adults and Adolescents. Washington, DC: Department of Health and Human Services; 2012.

30. Thompson MA, Aberg JA, Hoy JF, et al. Antiretroviral treatment of adult HIV infection: 2012 recommendations of the International Antiviral Society-USA panel. JAMA. 2012;308:387-402. 
31. Nash D, Wu Y, Elul B, Hoos D, El Sadr W, et al; International Center for AIDS Care and Treatment Programs. Program-level and contextual-level determinants of low-median CD4+ cell count in cohorts of persons initiating ART in eight sub-Saharan African countries. AIDS. 2011;25:1523-1533.

32. Marum E, Taegtmeyer M, Parekh B, et al. "What took you so long?" The impact of PEPFAR on the expansion of HIV testing and counseling services in Africa. J Acquir Immune Defic Syndr. 2012;60(suppl 3): S63-S69.

33. Wanyenze RK, Kamya MR, Fatch R, et al. Missed opportunities for HIV testing and late-stage diagnosis among HIV-infected patients in Uganda. PLoS One. 2011;6:e21794.

34. Luo C, Akwara P, Ngongo N, et al. Global progress in PMTCT and paediatric HIV care and treatment in low- and middle-income countries in 2004-2005. Reprod Health Matters. 2007;15:179-189.

35. Wettstein C, Mugglin C, Egger M, et al. Missed opportunities to prevent mother-to-child-transmission in sub-Saharan Africa: systematic review and meta-analysis. AIDS. 2012;26:2361-2373.

36. Mugglin C, Estill J, Wandeler G, et al. Loss to programme between HIV diagnosis and initiation of antiretroviral therapy in sub-Saharan Africa: systematic review and meta-analysis. Trop Med Int Health. 2012;17:1509-1520.

\section{APPENDIX. WRITING COMMITTEE}

Dorita Avila, ${ }^{1}$ Keri N. Althoff, ${ }^{2}$ Catrina Mugglin, ${ }^{1}$ Kara WoolsKaloustian, ${ }^{3}$ Manuel Koller, ${ }^{1}$ François Dabis, ${ }^{4}$ Denis Nash, ${ }^{5}$ Thomas Gsponer, Somnuek Sungkanuparph, ${ }^{6}$ Catherine McGowan, ${ }^{7}$ Margaret May, ${ }^{8}$ David Cooper, ${ }^{9}$ Cleophas Chimbetete, ${ }^{10}$ Marcelo Wolff, ${ }^{11}$ Ann Collier, ${ }^{12}$ Hamish McManus, ${ }^{9}$ Mary-Ann Davies, ${ }^{13}$ Dominique Costagliola, ${ }^{14}$ Brenda CrabtreeRamirez, ${ }^{15}$ Romanee Chaiwarith, ${ }^{16}$ Angela Cescon, ${ }^{17}$ Morna Cornell, ${ }^{13}$ Lameck Diero, ${ }^{18}$ Praphan Phanuphak, ${ }^{19}$ Adrien Sawadogo, ${ }^{20}$ Jochen Ehmer, ${ }^{21}$ Serge P. Eholie, ${ }^{22}$ Patrick C.K. Li, ${ }^{23}$ Matthew P. Fox, ${ }^{24,25}$ Neel R. Gandhi, ${ }^{26}$ Elsa González, ${ }^{27}$ Christopher K.C. Lee, ${ }^{28}$ Christopher J. Hoffmann, ${ }^{29,30}$ Andrew Kambugu, ${ }^{31}$ Olivia Keiser, ${ }^{1}$ Rossana Ditangco, ${ }^{32}$ Hans Prozesky, ${ }^{33}$ Fiona Lampe, ${ }^{34}$ Nagalingeswaran Kumarasamy, ${ }^{35}$ Mari Kitahata, ${ }^{12}$ Emmanuel Lugina, ${ }^{36}$ Rita Lyamuya, ${ }^{37}$ Saphonn Vonthanak, ${ }^{38}$ Valeria Fink, ${ }^{39}$ Antonella d'Arminio Monforte, ${ }^{40}$ Paula Mendes Luz ${ }^{41}$ Yi-Ming A. Chen, ${ }^{42}$ Albert Minga ${ }^{43}$ Jordi Casabona, ${ }^{44,45}$ Albert Mwango, ${ }^{46}$ Jun Y. Choi, ${ }^{47}$ Marie-Louise Newell, ${ }^{48}$ Elizabeth A. Bukusi, ${ }^{49}$ Kapella Ngonyani, ${ }^{50}$ Tuti P. Merati, ${ }^{51}$ Juliana Otieno, ${ }^{52}$ Mwebesa B. Bosco, ${ }^{53}$ Sam Phiri, ${ }^{54}$ Oon T. Ng,${ }^{55}$ Kathryn Anastos, ${ }^{56}$ Jürgen Rockstroh ${ }^{57}$ Ignacio Santos, ${ }^{58}$ Shinichi Oka, ${ }^{59}$ Geoffrey Somi, ${ }^{60}$ Christoph Stephan, ${ }^{61}$ Ramon Teira, ${ }^{62}$ Deo Wabwire, ${ }^{63}$ Gilles Wandeler, ${ }^{64}$ Andrew Boulle, ${ }^{13}$ Peter Reiss ${ }^{65}$ Robin Wood, ${ }^{66}$ Benjamin H. Chi, ${ }^{67}$ Carolyn Williams, ${ }^{68}$ Jonathan A. Sterne, ${ }^{9}$ Matthias Egger. ${ }^{1,13}$

(1) Institute of Social and Preventive Medicine (ISPM), University of Bern, Switzerland; (2) Department of Epidemiology, Johns Hopkins Bloomberg School of Public Health, Baltimore, MD; (3) Indiana University School of Medicine, Indianapolis, IN; (4) Institut de Santé Publique, Epidémiologie et Développement (ISPED), Université Bordeaux Segalen, Bordeaux, France; (5) CUNY School of Public Health, New York; (6) Faculty of Medicine Ramathibodi Hospital, Mahidol University, Bangkok, Thailand; (7) Vanderbilt University School of Medicine, Nashville, TN; (8) School of Social and Community Medicine, University of Bristol, United Kingdom; (9) The Kirby Institute, The University of New South Wales, Sydney, Australia; (10) Newlands Clinic, Harare, Zimbabwe; (11) Fundación Arriarán, Universidad de Chile, Santiago, Chile; (12) University of Washington School of Medicine Center, Seattle, WA; (13) Centre for Infectious Disease Epidemiology \& Research and Division of Epidemiology \& Biostatistics, School of Public Health \& Family Medicine, University of Cape Town, South Africa; (14) 1-UPMC Univ Paris 06, UMR_S 943, Paris, France; (15) Instituto Nacional de Ciencias Médicas y Nutrición, Salvador Zubirán, México D.F., México; (16) Research Institute for Health Sciences, Chiang Mai, Thailand; (17) British Columbia Centre for Excellence in HIV/AIDS, Vancouver, Canada; (18)
Academic Model Providing Access to Health Care (AMPATH), School of Medicine, College of Health Sciences, Moi University, Eldoret, Kenya; (19) HIV-NAT/Thai Red Cross AIDS Research Centre, Bangkok, Thailand; (20) CHU Sourô Sanou, Bobo-Dioulasso, Burkina Faso; (21) SolidarMed African HIV prevention and treatment program, Lucerne, Switzerland; (22) Service de Maladies Infectieuses et Tropicales (SMIT), CHU de Treichville, Abidjan, Côte d'Ivoire; (23) Queen Elizabeth Hospital, Hong Kong SAR, China; (24) Center for Global Health and Development and Department of Epidemiology, Boston University and Boston University School of Public Health, Boston, MA; (25) Health Economics and Epidemiology Research Office, University of the Witwatersrand, Johannesburg, South Africa; (26) Departments of Epidemiology, Global Health \& Infectious Diseases, Emory University Rollins School of Public Health, Atlanta, GA; (27) Instituto de Medicina Tropical Alexander von Humboldt, Universidad Peruana Cayetano Heredia, Lima, Peru; (28) Hospital Sungai Buloh, Sungai Buloh, Malaysia; (29) Aurum Institute, Johannesburg, South Africa; (30) John Hopkins University School of Medicine, Baltimore, MD; (31) Infectious Diseases Institute (IDI), Kampala, Uganda; (32) Research Institute for Tropical Medicine, Manila, Philippines; (33) Division of Infectious Diseases, University of Stellenbosch and Tygerberg Hospital, Cape Town, South Africa; (34) Research Department of Infection and Population Health, University College London, United Kingdom; (35) YRG Center for AIDS Research and Education, Chennai, India; (36) Ocean Road Cancer Institute (ORCI), Dar-es-Salaam, Tanzania; (37) Morogoro Regional Hospital, Morogoro, Tanzania; (38) National Center for HIV/AIDS, Dermatology \& STDs, Phnom Penh, Cambodia; (39) Fundación Huésped, Buenos Aires, Argentina; (40) Clinic of Infectious Diseases \& Tropical Medicine, San Paolo Hospital, University of Milan, Italy; (41) Instituto de Pesquisa Clínica Evandro Chagas, Fundação Oswaldo Cruz, Rio de Janeiro, Brazil; (42) Taipei Veterans General Hospital and AIDS Prevention and Research Center, National Yang-Ming University, Taipei, Taiwan; (43) Centre Médical de Suivi de Donneurs de Sang/CNTS/ PRIMO-CI, Abidjan, Cote d'Ivoire; (44) Centre d'Estudis Epidemiològics sobre ITS/VIH/SIDA de Catalunya, Badalona, Spain; (45) CIBER Epidemiología y Salud Pública (CIBERESP), Barcelona, Spain; (46) Zambian Ministry of Health, Lusaka, Zambia; (47) Division of Infectious Diseases, Department of Internal Medicine, Yonsei University College of Medicine, Seoul, South Korea; (48) Africa Centre for Health and Population Studies, University of KwaZulu-Natal, Mtubatuba, South Africa; (49) Family AIDS Care and Education Services (FACES), Kisumu, Kenya; (50) Tumbi Regional Hospital, Kibaha, Tanzania; (51) Faculty of Medicine Udayana University \& Sanglah Hospital, Bali, Indonesia; (52) Nyanza Provincial Hospital, MTCT-plus, Kisumu, Kenya; (53) Mbarara University of Science and Technology (MUST), ISS Clinic, Mbarara, Uganda; (54) Lighthouse Trust, Lilongwe, Malawi; (55) Tan Tock Seng Hospital, Singapore; (56) Departments of Medicine and Epidemiology and Population Health, Albert Einstein College of Medicine, New York, NY; (57) Department of Internal Medicine I, University Hospital Bonn, Bonn, Germany; (58) Hospital La Princesa, Madrid, Spain; (59) National Center for Global Health and Medicine, Tokyo, Japan; (60) National AIDS Control Program, Dar es Salaam, Tanzania; (61) HIVCENTER am Klinikum der Johann Wolfgang GoetheUniversität, Frankfurt, Germany; (62) Hospital Sierrallana, Torrelavega, Spain; (63) Makerere University Johns Hopkins University Research Collaboration (MUJHU Research collaboration), Kampala Uganda; (64) Department of Infectious Diseases, Bern University Hospital and University of Bern, Switzerland; (65) Academisch Medisch Centrum bij de Universiteit van Amsterdam, Amsterdam, The Netherlands; (66) Desmond Tutu HIV Center, University of Cape Town, South Africa; (67) Center for Infectious Disease Research in Zambia, Lusaka, Zambia; (68) Epidemiology Branch, Division of AIDS, National Institute of Allergy and Infectious Diseases, NIH, Bethesda, MD. 